Artículos

\title{
Derivas de lo personal: subjetividades en disputa en Tiempo pasado*
}

Drifts of the Personal: Subjectivities in Dispute in Tiempo pasado

Mónica Szurmuk a

DOI: https://doi.org/10.11144/Javeriana.cl24.dpsd

Universidad Nacional de San Martín, Perú

monicaszurmuk@gmail.com

ORCID: https://orcid.org/0000-0001-5867-7418

Recibido: 30 Abril 2017

Aceptado: 10 Julio 2017

Publicado: 30 Diciembre 2020

\section{Resumen:}

En este artículo se lee el libro Tiempo pasado: Cultura de la memoria y giro subjetivo. Una discusión de Beatriz Sarlo desde recientes desarrollos en los estudios de la memoria cultural que proponen la perdurabilidad de la misma a nivel social y colectivo. Planteamos que, aunque Sarlo critica la voz personal del giro subjetivo, utiliza su propia voz y sus propias predilecciones para interrumpir el desarrollo de los discursos que pone en cuestión. La crítica del giro subjetivo se realiza paradójicamente desde la subjetividad, exponiéndola a una variante del mismo interrogante al que ella somete a los textos que analiza: ¿cuál es el lugar de la primera persona en la narración del pasado reciente?

Palabras clave: Beatriz Sarlo, memoria, posmemoria, giro subjetivo, Argentina.

\begin{abstract}
:
In this article, I read Beatriz Sarlo's Tiempo pasado: Cultura de la memoria y giro subjetivo. Una discusión in the context of new scholarship in cultural memory studies, that proposes its transgenerational perdurability both at the a social and the collective level. I propose that Sarlo criticizes the personal voice of the "subjective turn" by deploying her own predilections, and therefore interrupting the discourses she purports to analyze. Sarlo's critique of the subjective turn is therefore carried out within her own subjectivity, inviting a question that echoes her own: what is the place of the first person singular in the narration of the recent past? Keywords: Beatriz Sarlo, memory, postmemory, subjective turn, Argentina.
\end{abstract}

\section{Recuerdos de infancia}

"El pasado es siempre conflictivo". Esta es la oración con la que Beatriz Sarlo abre Tiempo pasado: Cultura de la memoria y giro subjetivo. Una discusión (2005).Mucho menos contundente que el título del libro que lo precede cronológicamente, La pasión y la excepciónde 2003, Tiempo pasado continúa la línea de investigación propuesta por Sarlo sobre el pasado reciente. Sin embargo, y a diferencia de otros libros de la autora, la voz personal pareciera estar ausente en esta crítica feroz de Sarlo al giro subjetivo. Llamativamente, sin embargo, Sarlo ausenta a la primera persona narrativa — no nos habla de sí misma como en otros textos-, pero llena de subjetividad su mirada sobre los textos que critica. La crítica del giro subjetivo se realiza paradójicamente desde la subjetividad, lo que expone a Sarlo a una variante del mismo interrogante al que ella somete a los textos que analiza, ¿cuál es el lugar de la primera persona en la narración del pasado reciente?

Sarlo había inaugurado La pasión y la excepción hablando de su propia inversión biográfica en el tema — "hay razones biográficas en el origen de este libro y conviene ponerlas de manifiesto" (9)—, para luego relevar los momentos fundacionales de su historia personal en que entraron en su vida los ejes de la obra: Evita, el peronismo, Borges, la política. En Tiempo pasado las razones biográficas para la escritura están ocultas o ausentes y lo que predomina es una puesta en juicio de la primera persona que ganó el centro de la escena cultural en la Argentina de la postdictadura. Esta crítica se sustenta en un análisis que se dice objetivo en el que la metodología de investigación pareciera derrocar a la primera persona.

Notas de autor

a Autora de correspondencia. Correo electrónico: monicaszurmuk@gmail.com 
El tema de investigación del libro es el pasado reciente en la Argentina, un campo minado marcado por conflictos, políticas públicas y ejercicios personales. Sarlo tiene razón: el pasado es siempre conflictivo y el conflicto en el que ahonda es el que anuda recuerdos personales y memorias públicas que se insinúan como paralelos. Por un lado, el conflicto que se lleva en el marco de lo público y que puede resumirse en varias preguntas: ¿cuál es el uso público, no jurídico o moral, del testimonio? ¿Cuál es el rol de la primera persona en la constitución de un espacio público colectivo de memoria? Y la pregunta articulada por Sarlo misma "¿Qué relato de la experiencia está en condiciones de evadir la contradicción entre la fijeza de la puesta en discurso y la movilidad de lo vivido?" (La pasión 26).

La pregunta de Sarlo se inscribe en el campo de lo público, ¿cómo recuerdan las sociedades? Los lectores de Sarlo estamos habituados a la brillantez del momento en que la historia colectiva se cruza con lo personal. Fue ella quien introdujo en la crítica argentina el modo de pensar toda una cultura desde los detalles: ¡cómo era caminar por la Buenos Aires multilingüe entre 1920 y 1930?, ¿cómo era ser obrera y leer en el tranvía?, ¿ cómo era ser maestra? Sarlo ejercitó siempre esa manera de conjugar lo teórico con lo personal, atenta además a los registros de lo escrito, lo sentido, lo experimentado. Esa realidad escrita-leída-vivida, exhibida brillantemente en el análisis de las notas de La Opinión en La pasión y la excepción se le escapa entre los dedos en Tiempo pasado, porque hace caso omiso a la regla principal que describieron los que han teorizado el testimonio como género: hay que poner distancia con la lectura, reconocer el dilema de criticar formalmente el relato del trauma ajeno. El pacto identitario que establece el testimonio entre el narrador de su propia experiencia traumática requiere un tipo de distancia en el lector y crítico, una "retórica del particularismo", como la ha llamado Doris Sommer, es decir, un tipo de lectura que reconoce la falta de hospitalidad de aquellos textos que mantienen al lector a distancia.

No todo Tiempo pasado está dedicado al trauma, sin embargo. Para contestar la pregunta ¿cuál es el lugar de la subjetividad en la investigación social?, Sarlo acude a su bibliografía preferida: la escuela de Frankfurt. Los dos primeros capítulos del libro — “Tiempo pasado" y "Crítica del testimonio: sujeto y experiencia" - crean una sensación de coterie, de lectores que comparten lecturas y miradas sobre estas lecturas. Sarlo habla para los sarlianos que comparten sus lecturas, sus predilecciones personales, en un momento de cambio intenso. Desde los preceptos de la Escuela de Frankfurt, lee el testimonio, ignorando una nutrida bibliografía que se ha ocupado del género.

En el capítulo 5, en un gesto que la caracteriza, Sarlo introduce nuevas bibliografías, en este caso las de la posmemoria. Pero, a diferencia de otros investigadores a quienes publicó por primera vez traducidos al castellano en Punto de Vista -Edward Said, Stuart Hall, por ejemplo-, en este libro presenta autores que no le interesan y que cree desde el principio equivocados. Aparecen las propuestas de la posmemoria, principalmente los textos de James Young y Marianne Hirsch, autores que no habían sido publicados en castellano y que siguen sin serlo, como si la lectura desganada de Sarlo hubiera sido el kiss of death. Pero, antes de pasar a este ámbito, quisiera hacer un desvío propio por la subjetividad de Sarlo.

\section{El libro que no fue}

En Tiempo pasado, lo autobiográfico está relegado a dos breves referencias a lo personal — sus predilecciones literarias, un viaje a Terezín - y al agradecimiento que figura en la página 167, al final del libro. Dice Sarlo:

En 2003 fui miembro del Wissenschaftskolleg de Berlín, adonde llegué para escribir una biografía intelectual de los años sesenta y setenta. Con tiempo para revisar miles de páginas, abandoné ese proyecto. Leí demasiadas autobiografías y testimonios durante varios meses, y me convencí de que quería examinar críticamente sus condiciones teóricas, discursivas e históricas. El Wissenschaftskolleg acepta, como una especie de tradición liberal que lo enorgullece, estos cambios de programa. A esa comunidad intelectual berlinesa, va mi agradecimiento. (167) 
Coterie no more. Sarlo habla ahora a sus colegas berlineses. No explica qué cambió. La oración "Con tiempo para revisar miles de páginas, abandoné el proyecto”, Sarlo pareciera sugerir que las condiciones de posibilidad de una institución del primer mundo - el tiempo y las miles de páginas disponibles - fueron las que la llevaron a abandonar el proyecto. No sabemos cómo hubiera sido la biografía intelectual de los sesenta y los setenta. No he encontrado registros de este proyecto, no sé en qué consistiría la biografía colectiva de esta generación.

La distancia de los agradecimientos se repite a lo largo del libro. Sarlo le extiende su gratitud a la "comunidad intelectual berlinesa”, pero no incluye en los agradecimientos a ninguno de sus interlocutores argentinos. En una nota al pie le reconoce a Francine Masiello el haberle hablado del libro de Alicia Partnoy. La distancia que se establece con la época es monumental. Tiempo pasado es un registro también de la abismal distancia entre los y las que escribieron las "demasiadas" autobiografías y testimonios que leyó Sarlo durante esos meses y el libro que ella escribe, donde no los incluye ni les da nombre propio. No se agradece el costo de la escritura de una autobiografía. Y lo que se aprecia del Wissenschaftskolleg es el autorizar el cambio de dirección.

La descripción del proyecto que seguramente se presentó en la solicitud y que aparece en la página web del Wissenschaftskolleg lo presenta como una biografía ejemplar, escrita en primera persona, algo así como la voz de la maestra en La máquina cultural. Cito en extenso:

Biography of an Argentinian Intellectual

The project is an inquiry into the cultural history of Argentina in the past forty years. It aims to reconstruct the symbolic dimensions of events that signaled Argentina's XXth century: the development of populism as an ideology of the intellectual field; the radicalism of the sixties and seventies and its tense relations with modern art and the avant-garde; everyday life and intellectual resistance or exile during the military governments of the seventies and early eighties; the re-emergence of the public sphere and the academic field in the eighties. I intend to capture the "imaginaries" that set the conditions of the possibility of action and discourse, and that, at the same time, were reinforced by them. Remarks for Other Fellows

I will try to compose a biography of "an Argentinian intellectual", that is to say not a man or woman singled out from the many possible, but rather a type. "An Argentinian intellectual" means, in this project, an actor of the political and cultural space, situated towards the left in various graduations according to the transformation of the political scene.

The period to be considered begins in the sixties and stretches into the eighties. In the late sixties and early seventies, a new reading of Marxism, under the sign of the structuralist versions of the Marxist canon, had substantial influence on the left of the intellectual field and on vast zones of the Christian movement. Different versions of Marxism form part of the period culture and launched artistic and literary debates. For instance, in the case of literature, the place of Borges was under discussion and he was judged very differently on the right and the left of the critical space. The history of Borges' readings are a chapter of the transformations not only of criticism, but also of the ideological scene. During the eighties, a new reading of Argentine culture took place as a revision and a correction of positions sustained in the previous decades. The democratic transition brought many changes in the articulation of the intellectual field and modified its imagination, incorporating in it, as a decisive topic, the issue of human rights, history and memory.

The aim of the project is not to construct an ideal type, in the sense that Max Weber gave to this concept, but a typical character, in the sense coined Georg Lukács, and to grasp, in concrete historical situations, the grain of a lived experience. The "intellectual" should very probably be heard in the first person. (Wissenschaftskolleg zu Berlin)

Me interesa subrayar varios elementos de esta descripción. El primero es el hecho de que el objetivo del proyecto sea escribir una biografía de un/a intelectual argentino/a, probablemente en primera persona. Cuando Sarlo habla luego del proyecto — en la memoria anual de la institución, por ejemplo-, se refiere a la biografía de una generación, pero aquí insiste en esta abstracción, esta biografía de un/a intelectual que se concretiza en ese yo que contará las experiencias intelectuales de esa generación y las pasiones políticas. ¿Aparecerían en esa biografía la desaparición, la cárcel, el exilio? Me pregunto si esas experiencias no son las que hacen imposible el relato de Sarlo. ¿Qué queda sin palabras en las zonas donde se articula lo inefable?

El objetivo de comprender el núcleo de una experiencia vivida en situaciones es un buen resumen de lo que hace y ha hecho Sarlo. Pocos textos de la crítica argentina iluminan mejor este procedimiento que el relato de la maestra en La máquina cultural, capítulo ejemplar en el que se cuenta la historia de la educación argentina desde la perspectiva de una maestra. El exhaustivo trabajo de biblioteca y archivo que posibilitó la escritura del capítulo en primera persona está registrado en 15 páginas de notas para un texto de 65, donde se muestra el 
revés del proyecto de construcción del capítulo, una historia personal que encierra una clave para comprender la Argentina moderna y en la que la información de archivo se hace vida. Ahora bien, ¿̇se puede contar la experiencia del campo de concentración en primera persona como clave de interpretación?

Me he preguntado en qué consistiría la biografía de una generación y también cómo Tiempo pasado reemplaza a esa biografía. ¿Qué es lo que fue estéril, que no produjo texto en la propuesta anterior? Es un momento, además, de la historia argentina donde lo que se contó en primera persona fue el trauma experimentado durante el terrorismo de estado. Si bien Sarlo no reniega del uso legal o testimonial de la primera persona, sí lo hace del uso público de esa primera persona que según ella parece adueñarse del espacio público para ocuparlo todo.

Sabemos que Sarlo comienza pensando en este libro como biografía ficcional, que luego lo plantea como biografía colectiva - esto aparece en la Memoria de Wissenschaftskolleg-y después concluye con un texto que critica lo biográfico y particularmente lo autobiográfico como registro intelectual de un momento. El pasado es, sin duda, un lugar conflictivo.

\section{Respuestas}

Voy a ocuparme de dos lecturas que realiza Sarlo enfocándose primero en lo que percibe como una buena práctica y luego en lo que considera una mala práctica. La buena práctica aparece en el capítulo 4 resumida con la sentencia: "existen otras maneras de trabajar la experiencia" (94). En este capítulo analiza textos de Pilar Calveiro y de Emilio de Ípola, quienes se enfocan académicamente en situaciones concentracionarias (Calveiro) y carcelarias (De Ípola) que ellos mismos vivieron. El argumento es contrafáctico: a pesar de que tanto Calveiro como De Ípola podrían haber escrito testimonios, eligieron "procedimientos expositivos que implican un distanciamiento de los hechos" (96) y usaron la tercera en lugar de la primera persona.

En su análisis de Poder y desaparición; los campos de concentración en Argentina de Calveiro, Sarlo afirma que en este texto la verdad "se independiza de la experiencia" (114). Sin embargo y para evidenciar la validez de su afirmación, la crítica descubre la experiencia que cubre y oculta el texto académico. Según Sarlo, lo "singularmente original del libro de Calveiro es la decisión de prescindir de una narración de la experiencia personal como prueba de su argumento. El libro no prolonga en el presente su identidad de víctima. [...] Ella, Pilar Calveiro, la detenida-desaparecida de la dictadura, no viene a dar su testimonio sino a recibirlo de otros detenidos-desaparecidos" (119). Sarlo ejemplifica con la afirmación de Calveiro la bronca de los represores ante el suicidio de los prisioneros. Calveiro da ejemplos de otros.

Dice Sarlo: "Allí, su experiencia como prisionera habilita el manejo de otros testimonios, entre los cuales su experiencia está silenciosamente presente (el lector sabe) y al mismo tiempo elidida” (114, énfasis en el original). Sí, es cierto: nosotros, los lectores, sabemos. Ahora bien, si Sarlo afirma que el lector sabe, ¿por qué ahondar?, ¿por qué incluir los detalles?

Para probar su hipótesis, Sarlo hace un gesto impensable, cita un fragmento de una entrevista realizada en México por Juan Gelman a Calveiro, en la que la autora ubica una historia personal que está cubierta de una generalización académica:

Salto por la ventana de un primer piso alto de la Mansión Seré porque tengo claro que, a medida que pase el tiempo, voy a estar cada vez en peores condiciones físicas, que voy a perder la iniciativa. Entonces me digo que debo reaccionar ya. Había visto que la ventana del baño no estaba asegurada. Pido que me lleven y como estaba amamantando a mi hija menor, de 40 días, me daban más tiempo para que pudiera sacarme la leche. Entro al baño, abro la ventana y salto. De pie. Me tiraba a dos cosas la primera y fundamental, tratar de fugarme y perderme en Rivadavia... La segunda: si había guardias afuera me podían matar y así acababa la historia... Ellos escuchan el golpe de mi caída, me alzan y me llevan arriba, literalmente a patadas. (117)

En este fragmento Sarlo toma lo personal como evidencia haciendo un ejercicio de violencia interpretativa que atribuye, descubre, revela. 


\section{Violencias y lazos de filiación}

La niñez está marcada por esos momentos en que un evento se transforma en traumático y a la vez en fundacional. Lo sabe Sarlo quien ha ahondado como pocos en esas imágenes de infancia, esos momentos en que la Historia penetra en la historia personal y la cambia para siempre. Sarlo lo ubica en el marco de su casa familiar: el padre antiperonista que cuenta a la niña que murió Eva. "Eva había muerto cuando yo tenía diez años. Mi padre no me permitió ir a su interminable velorio en el Congreso" (12), dice en el prólogo a La pasión y la excepción.

Tiempo pasado está lleno de niños, quizá porque, como afirma Marianne Hirsch, la niñez como espacio de vulnerabilidad es exacerbada durante las catástrofes ${ }^{1}$. La infancia ofrece múltiples escenarios para magnificar y amplificar la crudeza de la catástrofe.

"Si tuviera que hablar por mî", dice Sarlo, "diría que encontré en la literatura (tan hostil a que se establezcan sobre ellas límites de verdad) las imágenes más precisas del horror del pasado reciente y de su textura de ideas y experiencias" (Tiempo pasado 63). Entre los textos que rescata está Dos veces junio de Martín Kohan del cual Sarlo cita textualmente la pregunta que define como "ilegible”: “:A partir de qué edad se puede empesar (sic) a torturar un niño?”. También aparece en Tiempo pasado el niño protagonista de Austerlitz de Sebald.

Frente a esta niña Beatriz Sarlo autobiográfica y a los niños literarios de Kohan y Sebald, aparecen varias niñas: la beba que Calveiro ya no amamanta, pero para la que se sigue sacando leche y las dos hijas de sobrevivientes, Albertina Carri y Marianne Hirsch. Sarlo regaña tanto a una como a otra: niñas malas que no entendieron su rol en la historia y se dedican a producir "un almacén de banalidades" (Hirsch) o un filme donde la hija que busca a los padres los malentiende (Carri).

Tanto en el análisis de la película Los rubios de la cineasta argentina Albertina Carri y del paradigma de la posmemoria como fue desarrollado por Marianne Hirsch, Sarlo apela a lo personal para la descalificación. La hija de desaparecidos es narcisista y se multiplica a sí misma en la pantalla a la vez que malentiende la historia de sus padres; Hirsch reflexiona sobre la posmemoria aun cuando es una hija de judíos centroeuropeos desplazados por el nazismo "a los que les ha ido bien en América del Norte" (134).

En el caso de Los rubios, Sarlo considera que "el film interroga a personas a las que considera unilaterales o equivocadas. El malentendido es comprensible” (148). Ahora bien, no queda duda de que Sarlo considera a Hirsch y a Carri unilateralmente equivocadas, y por eso este malentendido sea quizá comprensible también. Como señala Ana Amado:

[...] desarrolla su crítica con una argumentación que, de este modo, encuentra diferencias entre los testimonios de los hijos, que considera menos desde el canal expresivo que utilizan o por la calidad que sus producciones demuestran sino por sus antecedentes personales, entre ellos los de clase social de sus familias de origen. (162)

Ahora bien, ¿es necesario el ataque personal?, porque el blanco de la crítica de Sarlo es Albertina Carri niña, el complejo proceso por el cual, desdoblada en directora, actriz y protagonista, esta cuenta el propio testimonio de infancia. La despiadada lectura del filme de Carri ejercita una violencia contra quien cuenta una historia personal que, recordémoslo, es traumática. Sarlo oscila entre criticar la obra y criticar a Carri. La potencialidad de la película de Carri se encuentra exactamente en ese entrelugar donde la nena desea tener a sus padres, añora su regreso y agradece a la vez la domesticidad de la vida en el campito, mientras, lo sabe ahora de adulta, sus padres estaban en el campo de concentración.

Como una niña malcriada, Carri es comparada desfavorablemente con los otros hijos de desaparecidos, los que continúan desde la perspectiva de Sarlo el compromiso político de sus padres desde un modo que es legible para la crítica. Sarlo le cuestiona a Carri la manera en que entrevista a Lila Pastoriza y Alcira Argumedo presentándolas como tías viejas, y se adueña un poco del rol de tía vieja, reclamándole a Carri respeto por sus mayores y por su modo de hacer política. Hay una crispación en el texto frente a los recuerdos infantiles de Carri, una llamada a producir un filme que responda a la generación de sus padres — situación adelantada en 
la escena de la película en que una carta del INCA requiere lo mismo del proyecto de la directora-. Sarlo acusa a Carri de malentender la historia de sus padres y a Hirsch de realizar un gesto teórico "más amplio que necesario" (132).

\section{En primera persona}

Tiempo pasado se construye como una advertencia sobre los riesgos de perder de vista la historicidad y la fuerza política del pasado reciente. Lo que se pierde de vista en esta reflexión es, como señala Andreas Huyssen, la potencialidad de las memorias individuales para evitar que el discurso de los derechos caiga muy pronto en una abstracción histórica (616-617). En un tono similar, Pilar Calveiro sostiene que

relegar el testimonio a otra fuente de archivo es ignorar la potencia de la denuncia. || ¿Llegará el momento de relegar los testimonios de la dictadura argentina al archivo, acallar las voces, contar solamente desde afuera? Quizá. Si tuviera que hablar por mí, diría que todavía se necesitan las voces en primera persona, los relatos que aún 41 años después del golpe militar revelan nuevamente lo inconcebible.

Hacia el final de Tiempo pasado Sarlo habla de un viaje propio a Terezín, guiada por la novela Austerlitz de Sebald, quien, según ella, "muestra en qué extremos se mueve cualquier empresa reconstructiva: desde la pérdida radical de la identidad a su enajenación en el recuerdo empujado por el deseo, siempre imposible, de una memoria omnisciente" (166). La reconstrucción que buscan Hirsch y Carri, y muchos más en los paradigmas de la posmemoria, saben de esa imposibilidad, pero confían en la posibilidad política y ética de la búsqueda.

\section{Referencias}

Amado, Ana. La imagen justa. Cine argentino y politica (1980-2007). Colihue, 2009.

Calveiro, Pilar. "El testimonio como narración". Conferencia presentada en el Congreso de Filosofía de la Benemérita Universidad de Puebla, 2009.

Hirsch, Marianne. Family Frames: Photography, Narrative and Postmemory. Harvard University Press, 1997.

Hirsch, Marianne. The Generation of Postmemory. Writing and Visual Culture After the Holocaust. Columbia University Press, 2012.

Huyssen, Andreas. "International Human Rights and the Politics of Memory: Limits and Challenges". Criticism, vol. 53, n. ${ }^{\circ}$, sep.-dic. 2011, pp. 607-624.

Sarlo, Beatriz. "A Borgesian Library in Grunewald's Locus Amoenus". Wissenschaftskolleg zu Berlin, Institute For Advanced Study. Jabrbusch 2002/2003, 2004, pp. 142-146.

Sarlo, Beatriz. La máquina cultural. Maestras, traductores y vanguardistas. Ariel, 1998.

Sarlo, Beatriz. La pasión y la excepción. Siglo XXI, 2003.

Sarlo, Beatriz. Tiempo pasado: cultura de la memoria y giro subjetivo. Una discusión. Siglo XXI, 2005.

Sommer, Doris. Proceed with Caution When Engaged With Minority Writing in the Americas. Harvard University Press, 1999.

Szurmuk, Mónica. "Posmemoria”. En Mónica Szurmuk y Robert McKee Irwin, Diccionario de estudios culturales latinoamericanos. Siglo XXI, 2010.

Wissenschaftskolleg zu Berlin. "Beatriz Sarlo". https://www.wiko-berlin.de/en/fellows/fellowfinder/detail/2002-sarl o-beatriz/ 


\section{Notas}

* Artículo de investigación.

1 En su último libro, The Generation of Postmemory: Writing and Visual Culture After the Holocaust, Marianne Hirsch dedica varios capítulos a la infancia y los usos que han tenido las fotografías de archivo en las que aparecen niños en la producción artística y literaria de descendientes de sobrevivientes de hechos traumáticos. Es muy interesante que en el apartado dedicado a las imágenes de niños, Hirsch incluya su propia experiencia de ser "haunted" por estas imágenes (160), además de las experiencias infantiles de Susan Sontag (103) y Alice Kaplan (104).

\section{Licencia Creative Commons CC BY 4.0}

Cómo citar este artículo: Szurmuk, Mónica. "Derivas de lo personal: subjetividades en disputa en Tiempo pasado”. Cuadernos de Literatura, vol. 24, 2020. https://doi.org/10.11144/Javeriana.cl24.dpsd 